(BYMV)Bean yellow mosaic تثخيص سلالات فايروس موزائيك الفاصوليا الأصفر Phaseolus vulgaris على نباتات الفاصوليا virus potyvirus

\title{
Identification strains of Bean Yellow Virus potyvirus (BYMV) on bean Phaseolus vulgaris in Iraq
}

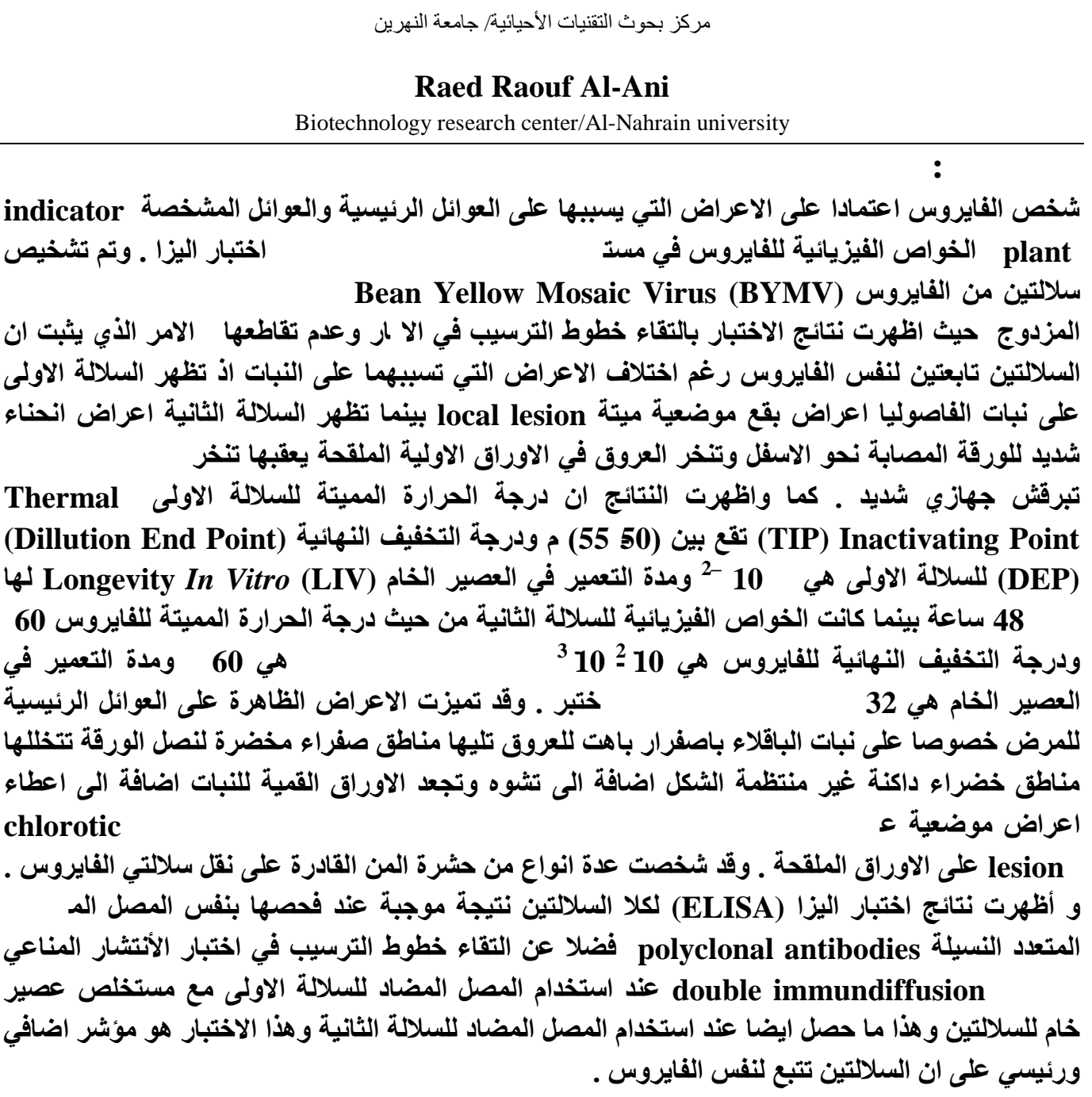

Abstract

Several methods were used to identify the virus, such as indicator plants, physical properties, manners transmission by aphids and ELISA test and among indicator plants two strains of BYMV were identified. The first one was showed a necrotic local lesion on bean while the second one was showed strong epinasty, veinal necrosis in inoculated leaves then it caused top necrosis at last severe systemic mottle. This two different symptoms gives a positive reaction at ELISA test and this test was indicated that the two symptoms is belong for two strains of bean yellow mosaic virus ( BYMV).The physical properties for the first strain about the Thermal Inactivating point (TIP) was 50-55c while the second strain 
was 60c and the dilution end point (DEP)for the first strain was $10^{-2}$ but it was $10^{-2}-10^{-3}$ for the second one and the longevity in vitro (LIV) for the first strain 48 hrs at room temperature and the main transmission by insect was achieved by several species of aphids. The double immunodiffution test in agar have been showed meeting of two precipitin line without cross in this two lines when used antiserum of the first strain of virus against the two sap of infected plants with both strains of virus and this test was used in the second strain against sap of the both infected plants too with the two strains of the virus and this test was additional indication that the two symptoms in bean were belonged to a two different strains to the same virus.

يصاب محصول الفاصوليا Phaseolus vulgaris بفايروسات عديدة في العالم [1] وتنتقل هذه الفايروسات

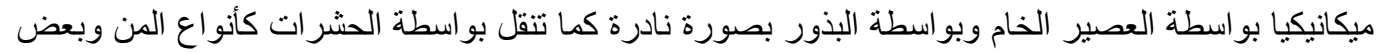

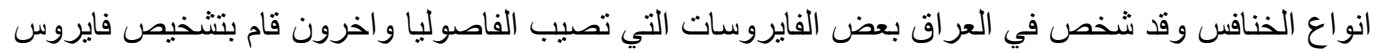

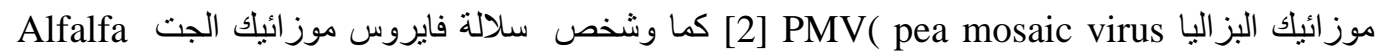
(AMV) mosaic virus

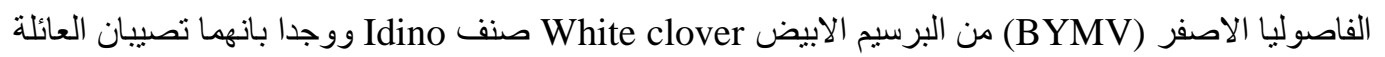

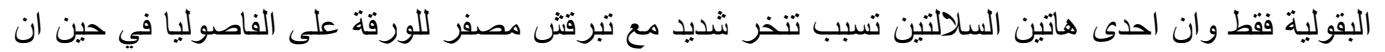

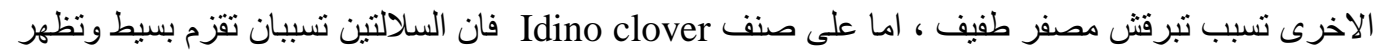

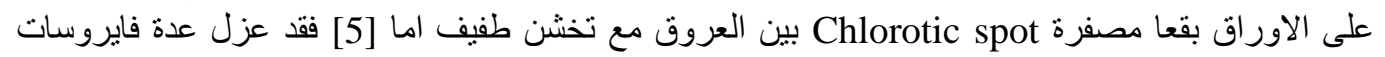

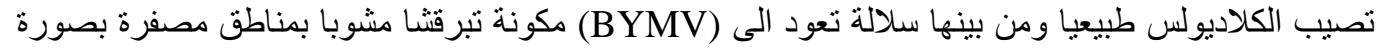

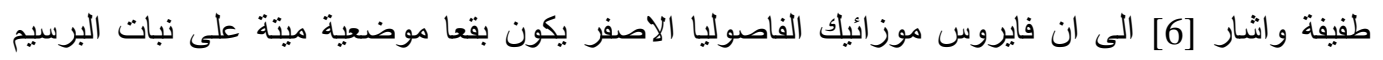

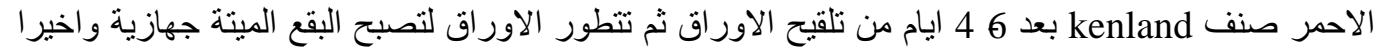

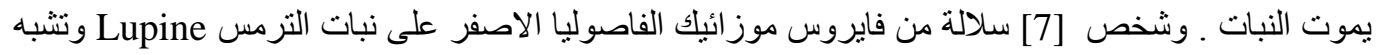

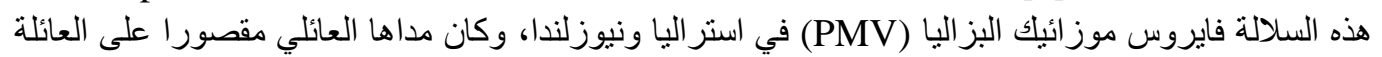

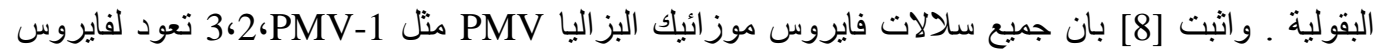

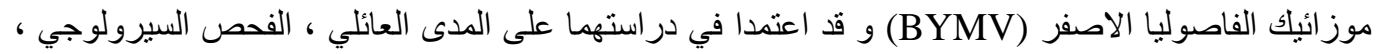

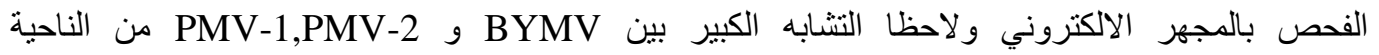

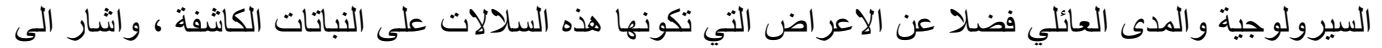

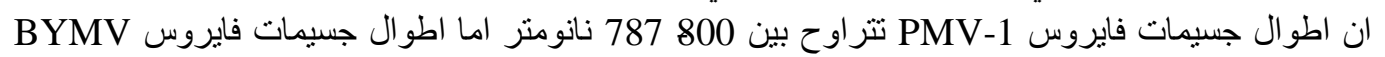

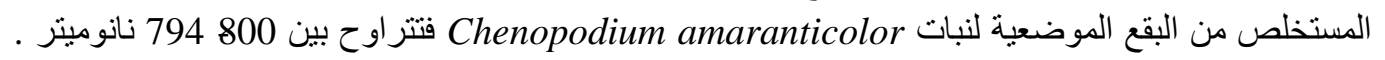
وقد عزل [9] في بلجيكا سلالة تعود لفايروس موزائيك الفاصوليا الاصفر من نبات الباقلاء تنقل ميكانيكيا الى الى

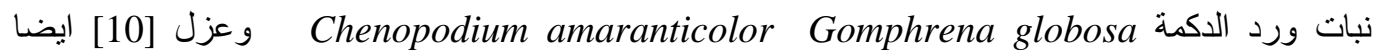
سلالة تعود لنفس الفايروس من نبات Viciaa sativa, vetch تنقل ميكانيكيا الى عو ائل نباتية مختلفة، وعزلت

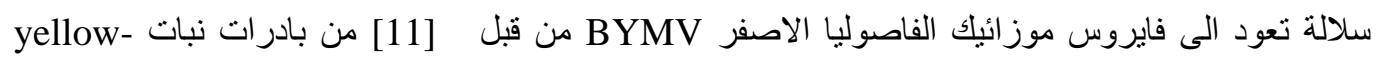
Cladratis lutea و wood

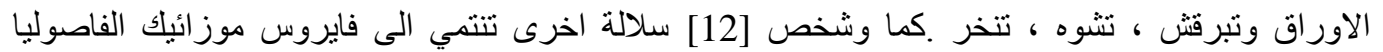

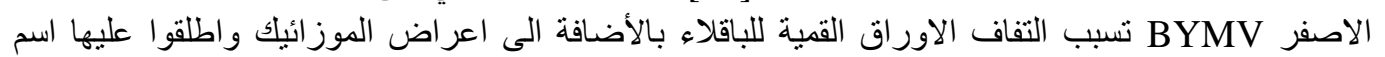

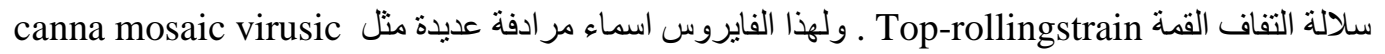

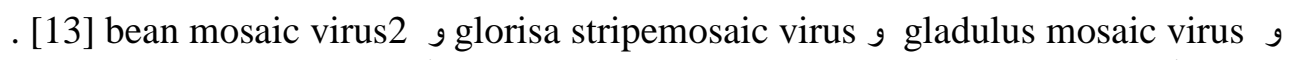
ونظر الأهمية هذا الفايروس وسلالاته على نبات الفاصوليا و العو ائل الأخرى فقد اجريت هذه الدراسة .

اولا: تثخيص الفايروس 
اعتمد في تثخيص الفايروس عدة طرق مكملة لبعضها وكما هو متبع في تثخيص الفايروسات النباتية وحسب ما

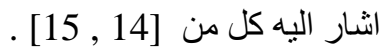

:

وشملت الدراسة الاعراض الخارجية على العائل الرئيسي نبات الفاصوليا والعو ائل الشخصة في البيت البلاستيكي . جمع العينات

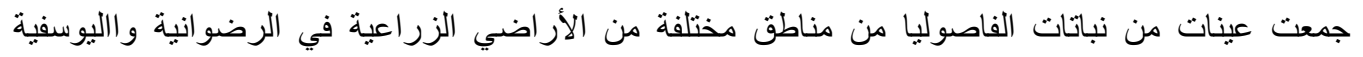

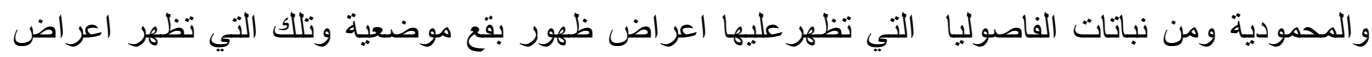

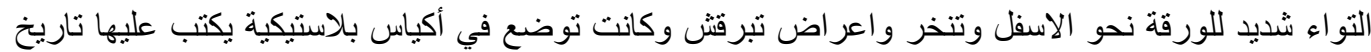



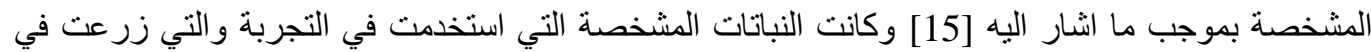

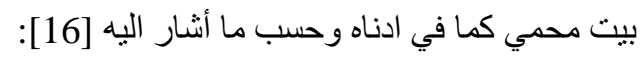

Phaseolus vulgaris, Pisum sativum, Vicia faba, Chenopodium amararanticolor, Ch. Quinioa, .Gomphrena globosa, .Nicotiana tabaccum , Spinacea oleracea, Tetragonia expansa

$$
\text { نقل الفايروسات بالمن }
$$

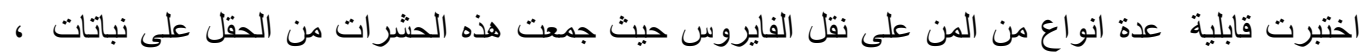

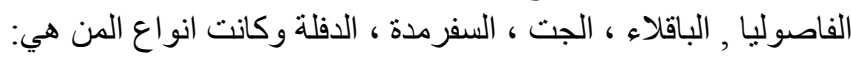

Ayrthosiphum pisum, Aphis fabae , A. crccivora , A. neri , Myzus persicae, Rhopalosiphum padi

تم تثخيص هذه الانواع من حشرات المن بالاستعانة [17] وتأكيد تنخيصها في متحف التاريخ الطبيعي .

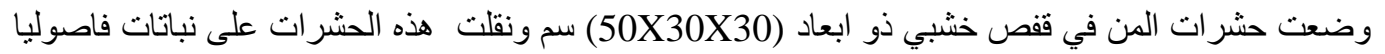

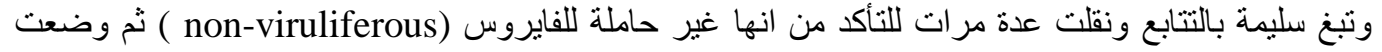

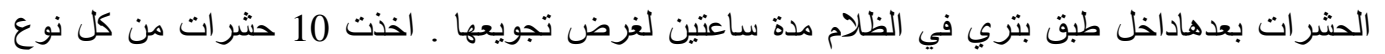

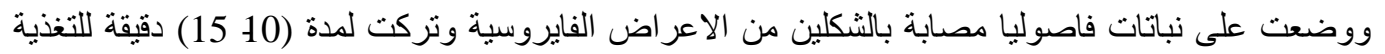

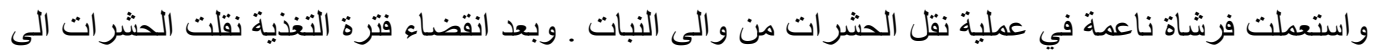

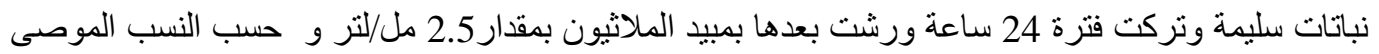

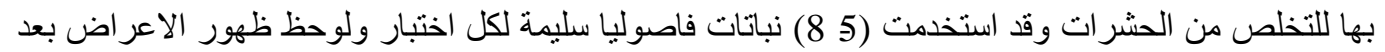

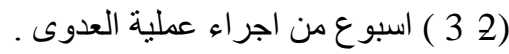
الفحوصات السيرولوجية

تم استخدام فحص اليزا (ELISA) Enzyme Linked Immunosorbent Assay (تاستخدام مصل مضاد ومصل مضاد مرتبط بالأنزيم متعدد النسيلة Polyclonal antibodies منتج من شركة Switzerland bioreba

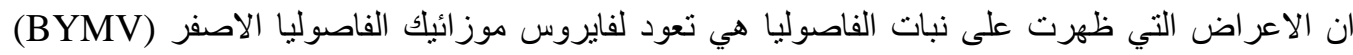
تإئه Bean Yellow Mosaic Virus تنقية فايروس موزائيك الفاصوليا الاصفر اعتمدت طريقة [18] و التي اشار اليها [19]عند تنقيته فايروس البطاطا M M في تنقية فايروس موزائيك

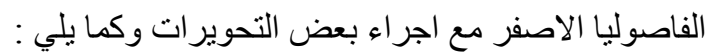

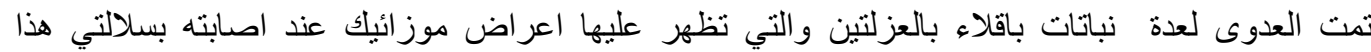

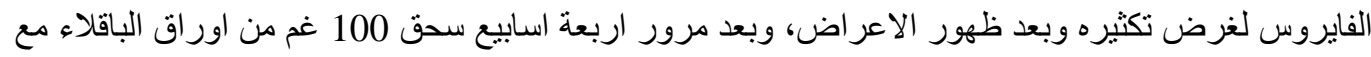

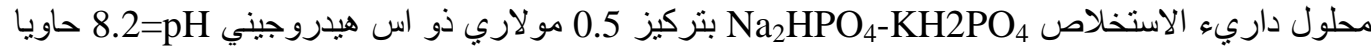

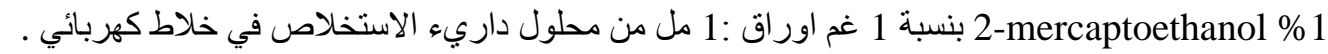

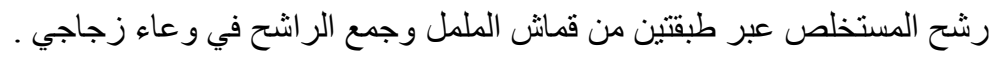


ولغرض ترويق العصارة اضيف للراشح 8 مل من البيونانول لكل 100 مل من المستخلص مع الاستمرار في

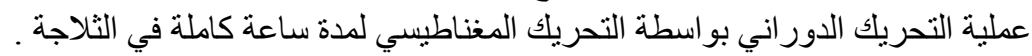

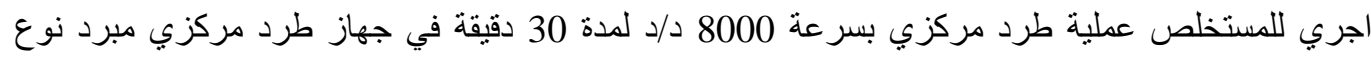

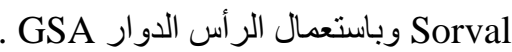

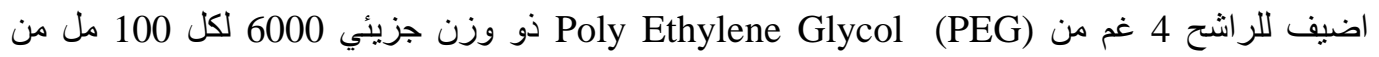

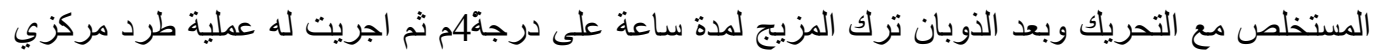

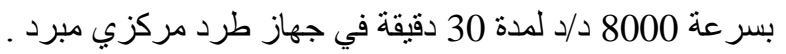

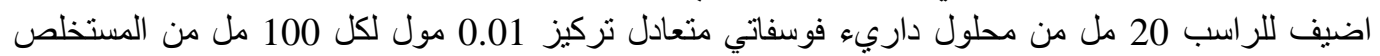

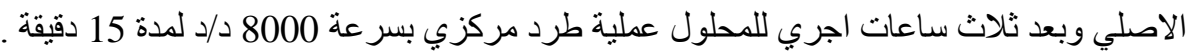

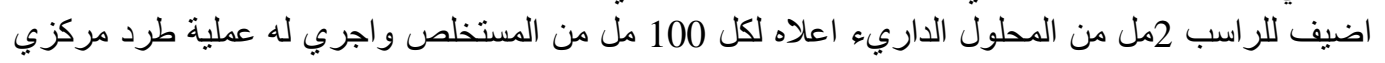

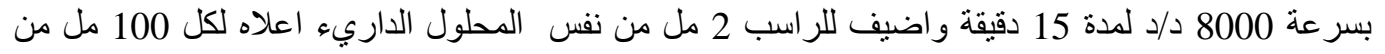

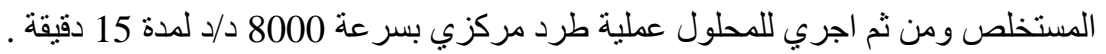

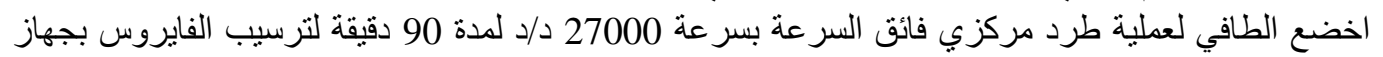

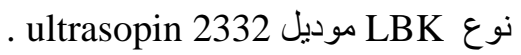
اذيب الراسب في محلول داريء فوسفاتي تركيز 0.5 مو لاري ذو اس هيدروجيني 8.2 وبذللك تم الحصول على

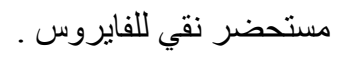
تقدير تركيز الفايروس تلفيروس

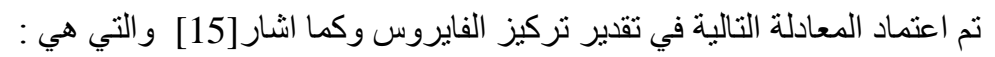

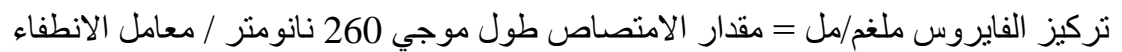

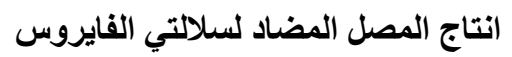
استخدمت ارانب نيوزلندية وزن 6 باوند في انتاج المصل المضايرت المضاد وتمت عملية الحقن للأرانب بمستحضر

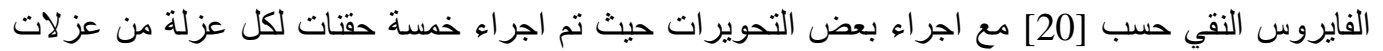

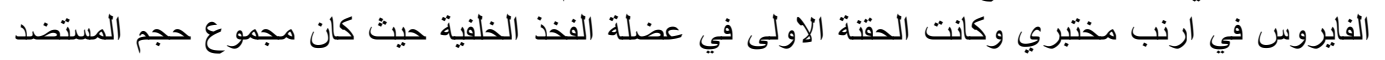

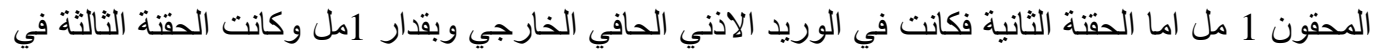

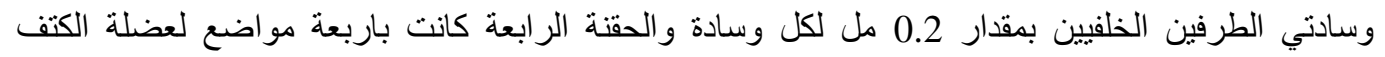

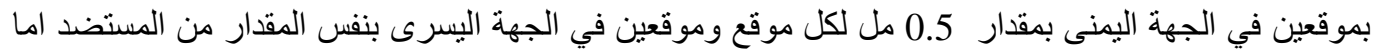

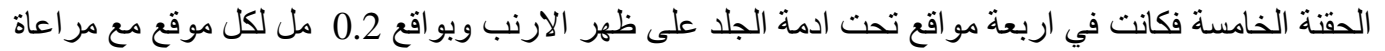

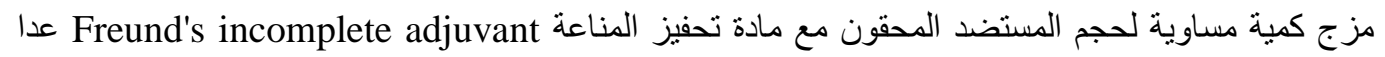

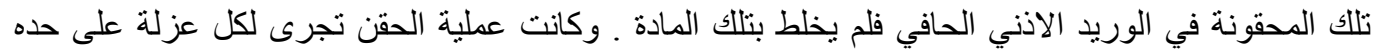

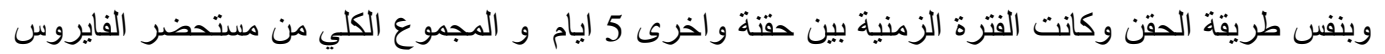

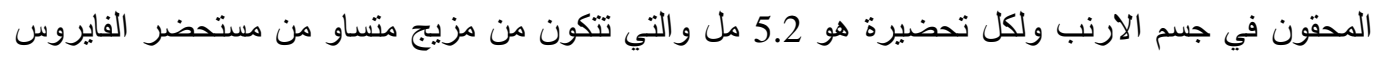

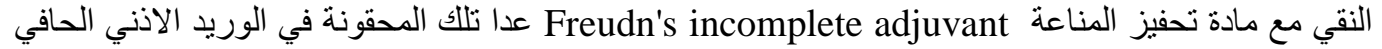
فلم تخلط بتلك المادة كما وتم سحب 10 مل من اذن كل ارنب قبل عملية الحقن للمقارنة .

اخذت عينة من مصل الارنب الممنع من الوريد الأذني الحافي الخارجي واختبر احتو ائها على الاجسام المضادة

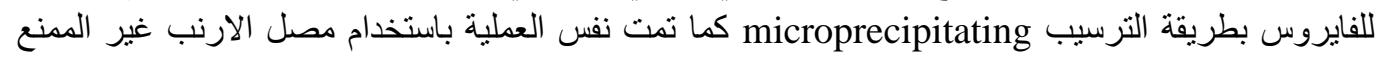
وكررت العملية ثلاث مرات ودونت التربن النتائج .

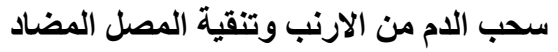

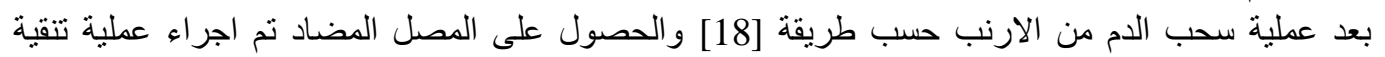

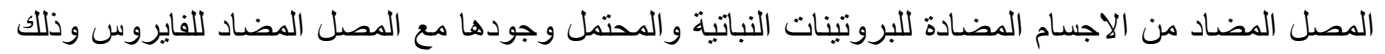

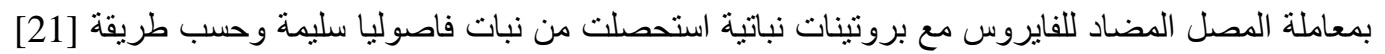

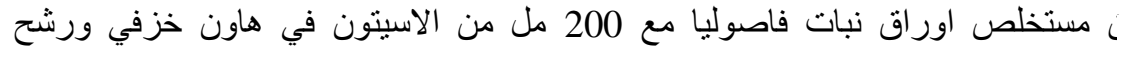


المستخلص خلال ورق ترشيح و اتمان 4 على قمع بخنر بواسطة الاسيتون حتى اصبح المستخلص عديم اللون

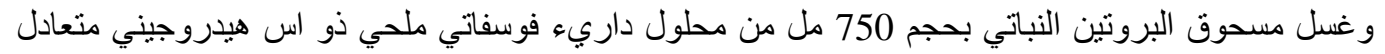
pH

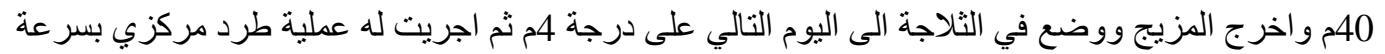

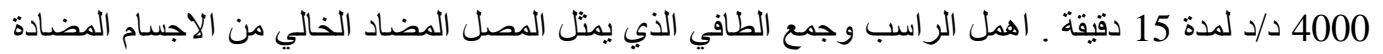

\section{Agar immuno diffution test}

للبروتينات النباتبة .

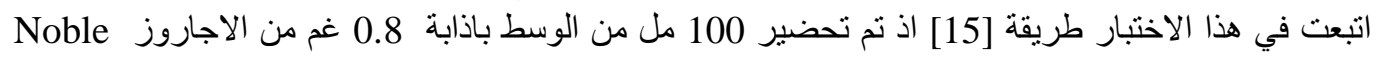

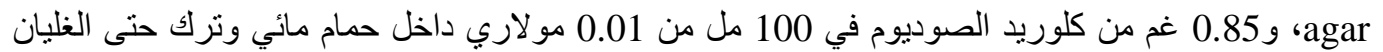

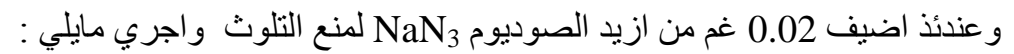

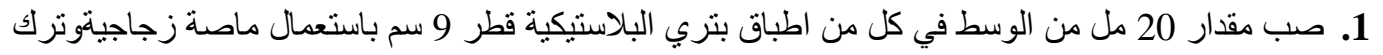
حتى يتصلب على سطح مستوي . 2. بعد ساعة من عملية الصب تم عمل حفرة في الوسط المتصلب باستخدام ثاقب فلين قطر 5 ملم وكانت المسافة

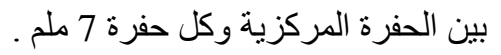

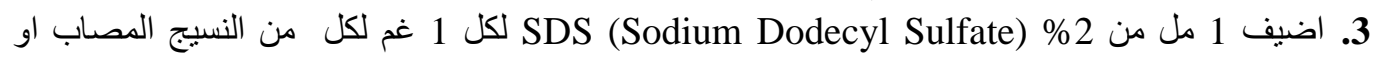

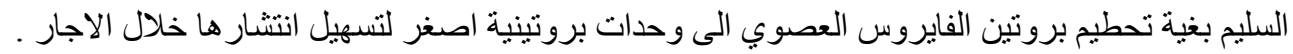

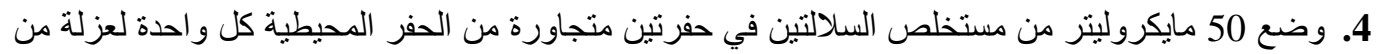

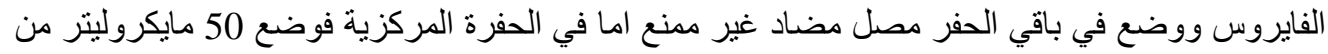

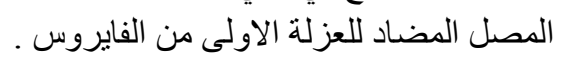

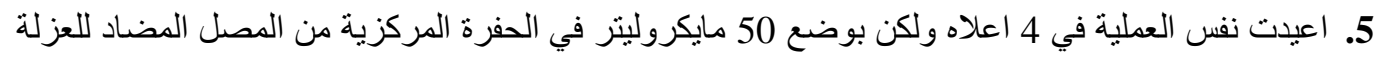

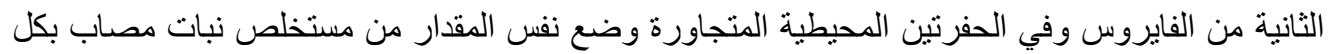

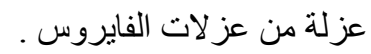

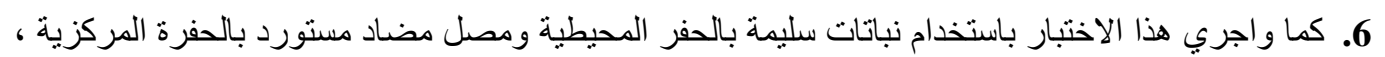

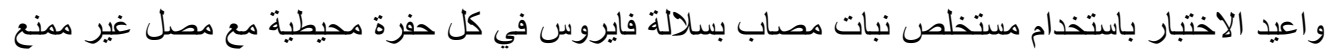

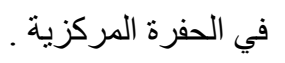

فحص العلاقة السيرولوجية بين عزلتي الفيرير التروس تم اجر اء فحص الترسيب الدقيق microprecipitating بين عزلة الفئلة الفايروس المنقاة الاولى مع الاجسام المضادة الإنة

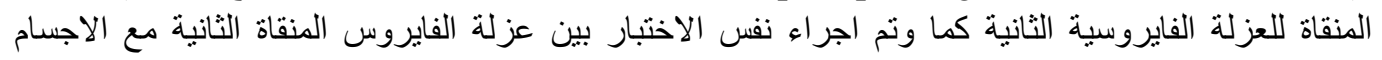

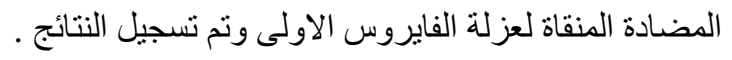

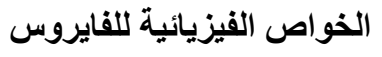

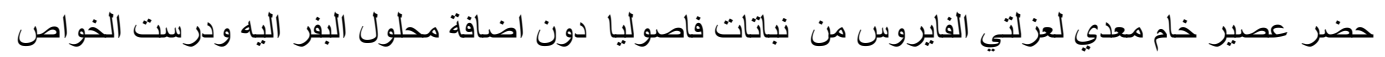

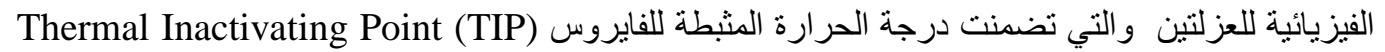

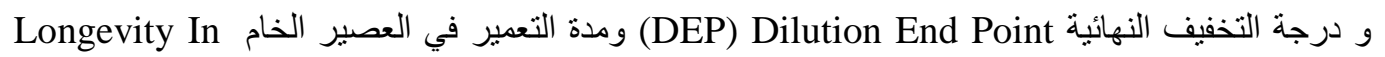
• وكما أثنار [22) vitro

Harvester, Black Turtle, لوحظت الاعراض على نبات الفاصوليا والتي استخدمت فيها الاصناف Bountiful, Cotia

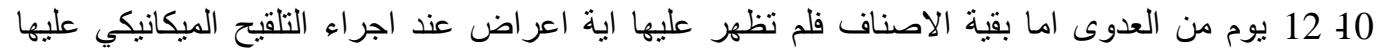

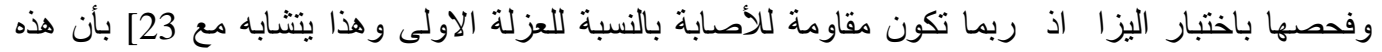

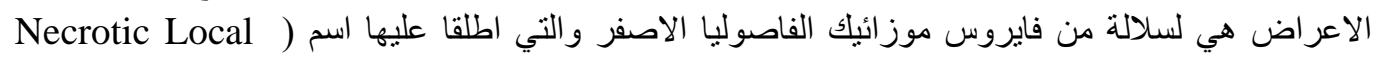

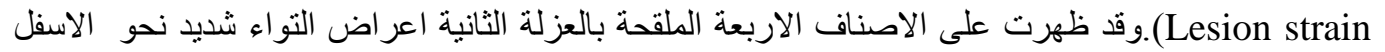

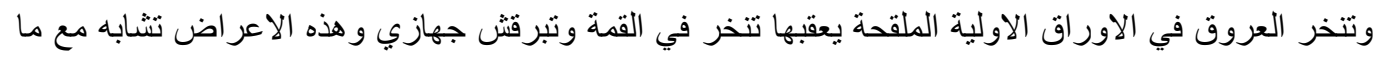

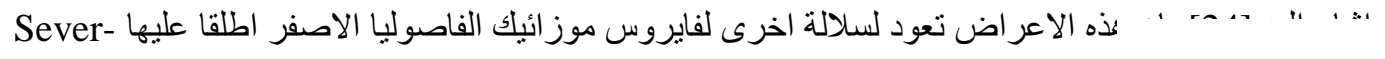




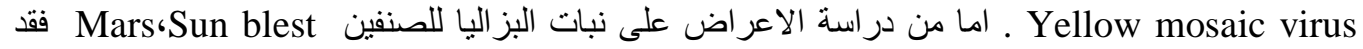

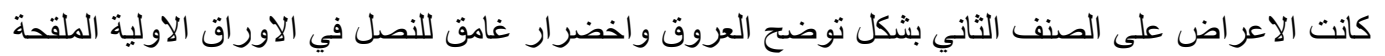

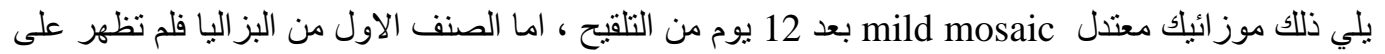

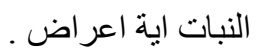

استجاب نبات Chenopodium amaranticolor للفايروس باعطاء بقع موضعية صفراء على الاوراق

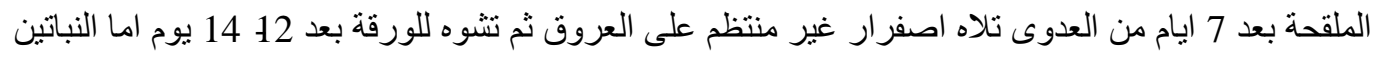
Chenopodium quinoa, Tetragonia expansa

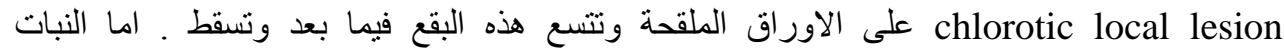
Chenopodium murale الصفات الفيزيائية للفايروس :

اوضحت النتائج بان السلالة الاولى للفايروس والتي تعطي اعراض الفئل بقع موضعية ميتة بان درجة الحرارة

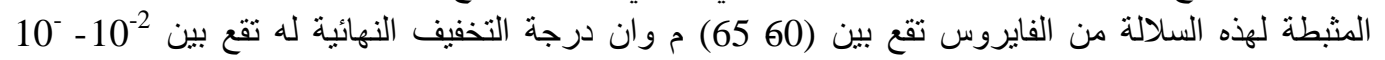

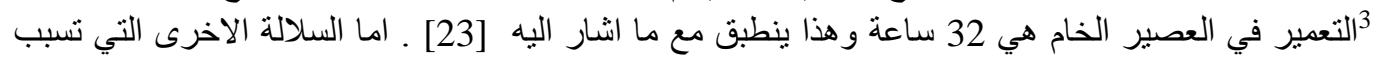

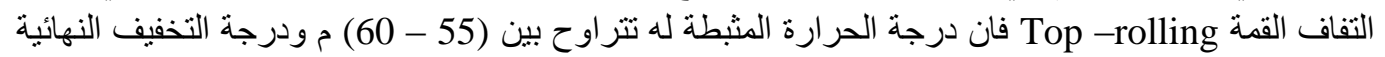

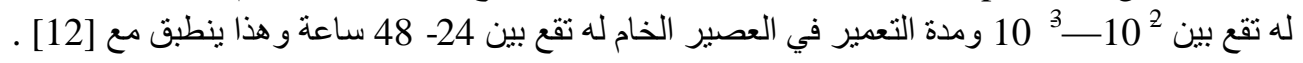
نقل الفايروس بواسطة حشرات المن اظهرت النتائج بان انواع حشر ات المن التالية كانت قادرة على نقل الفرائل الفايروس من نبات الفاصوليا الى نباتات

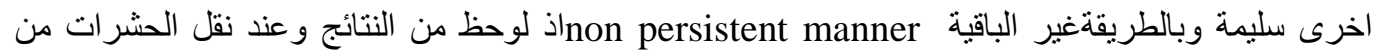

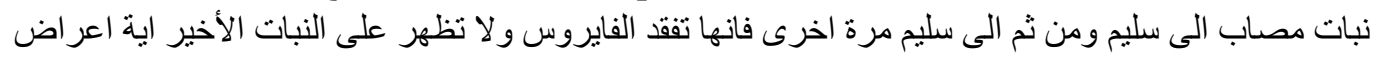

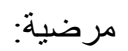

.Aphis fabae, A. craccivora, Myzus persicae, Acrythosiphum pisum, Aphis neri Ropalosiphum padi

اختبار اليزا : ELISA test

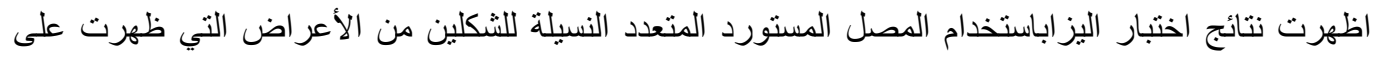

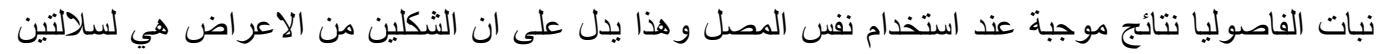

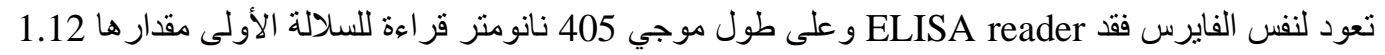
بينما كانت قر اءة الجهاز للسلالة الثانية 1.09في حين كانت القراءة لمستخلص النبات السليم 0.32 ـ

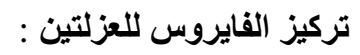

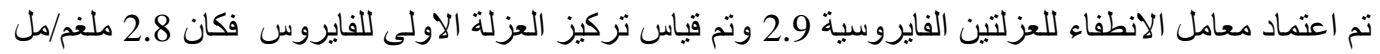

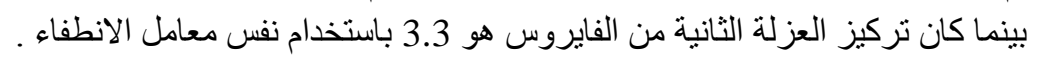

اظهرت نتيجة الفحص بالترسيب الدقيق بعد الفحص بالمجهر ظهور راسب عند خلط 50 مايكروليتر من المصل

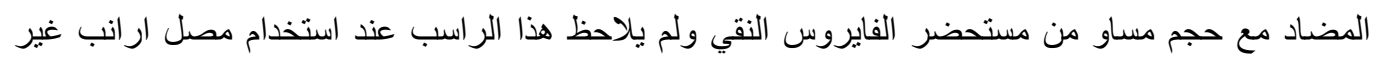

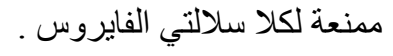

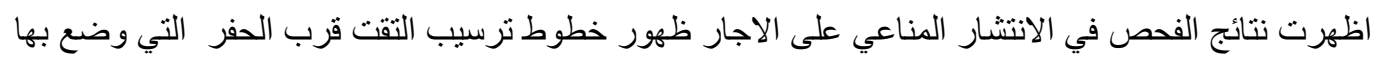

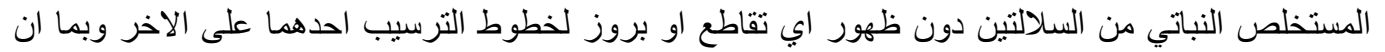

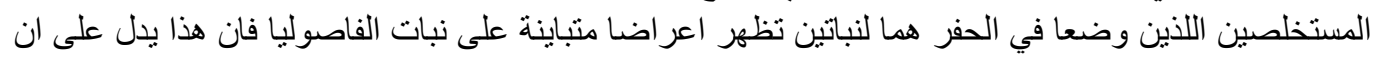

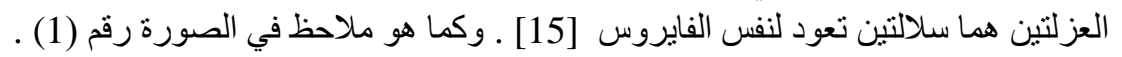




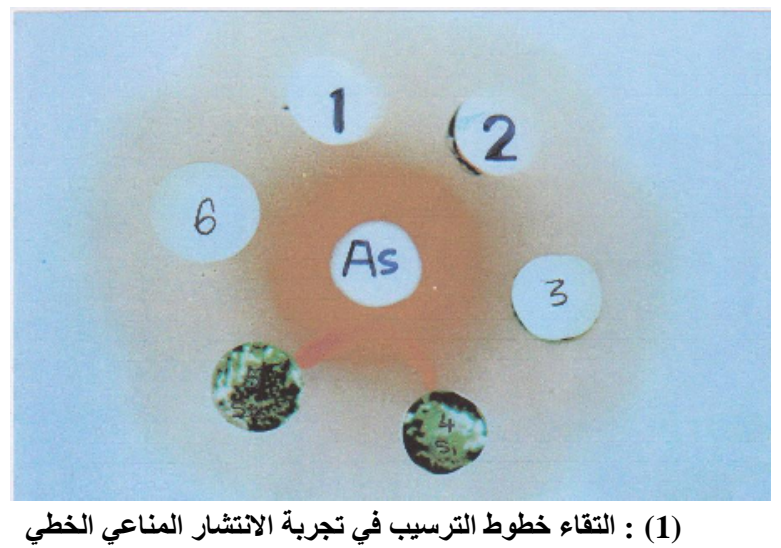

السيرولوجية بين العزلتين الفايروسية

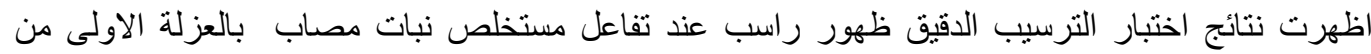

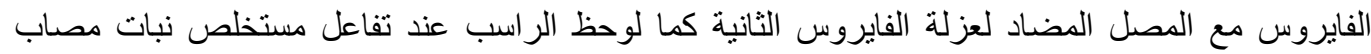

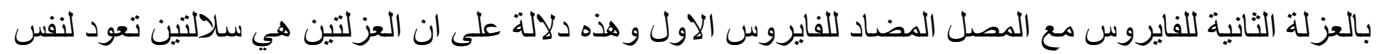

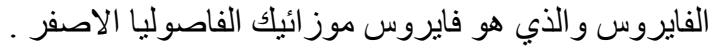
تثخيص الفايروس وسلالاته

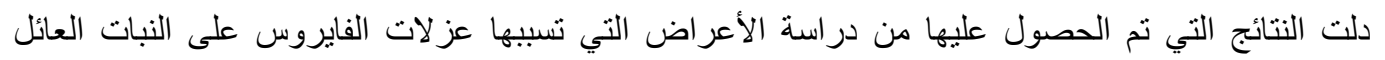

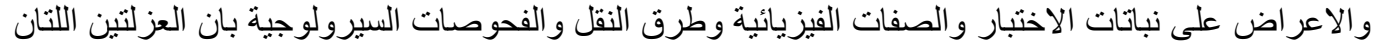

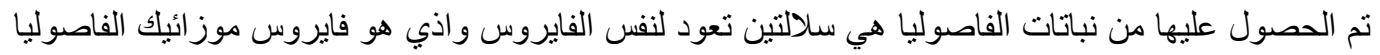
الأصفر Bean (Bean Yellow Mosaic Virus)

بما ان الاعر اض التي ظهرت على نبات الفاصوليا للعزلتين كانت متباينة وان اختبار اليزا اعطى نتيجة ايجابية

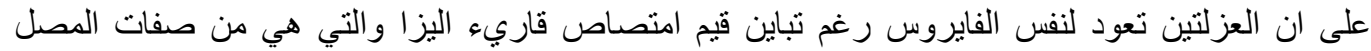

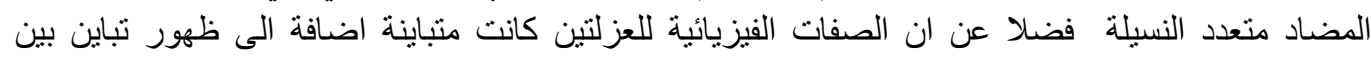

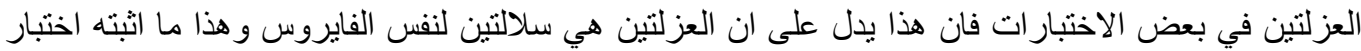

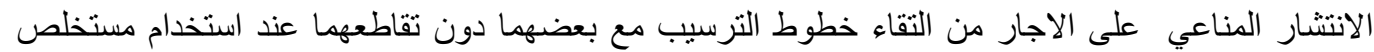

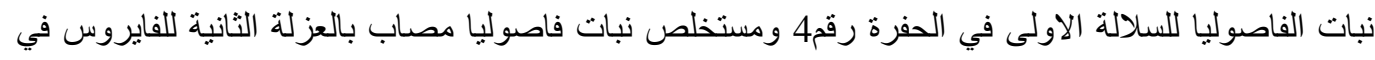

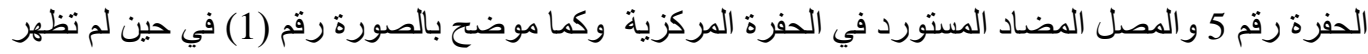

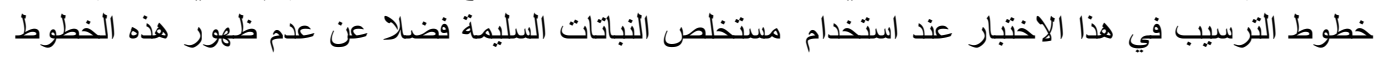

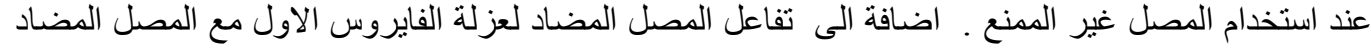

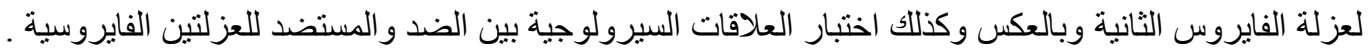

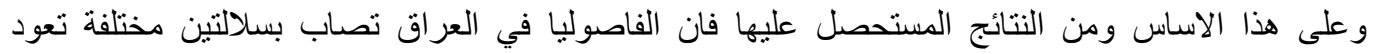

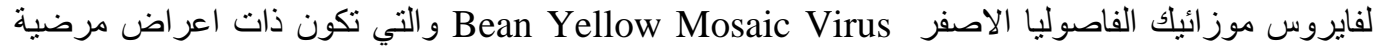

متباينة.

1. Smith,K.M.(1972).A text book of plant virus, third edition, Longman Group and Ltd.London.

2. Salama,E.A., K.M.El-Adil, A.H.El-Behadili and H.A.Majeed.(1979).Viruses causing mosaic disease on broadbean in Iraq $.3^{\text {rd }}$ Egypt phutopatholo. Congress.(1979).pp.75-91.

3. Salama, E.A. and A.H.El-Behadli.(1979).Strains of alfalfa mosaic virus on broadbean in Iraq.Bull.Nat.Hist.Res.CENTER.7:101 -112. 
4. Houston,B.R.and J.W.Oswald(1953). The mosaic virus disease complex adino clover.Phytopathology..43:271-276.

5. Barkeley,G.H. (1955). Some viruses affected Gladiolus.Phytopathology ,43:111115.

6. Diacham,G.H.and ,L.Henson.(1956).Clones of kenland red clover as local lesion hosts for bean yellow mosaic virus.Phytopathology.46:10-11.

7. Corbett,M.K. (1958).A virus disease of Lupines caused by bean yellow mosaic virus and pea mosaic virus. Aust.J.Biol.Sci.21:429-437.

8. Taylor,R.H.and P.R.Smith.(1968) .The relationship between Bean yellow mosaic virus and pea mosaic virus. Aust.J.Biol.Sci.21:429-437.

9. Poland,G.,(1966).Research on a virus causing mosaic field bean ( Vicia faba)Parasitica .22:277-284. Abstr.Rev.appl.Ent.(A)56-233.

10. Poland, G.(1969).Study on virus disease of vetch Vicia fabbae Parrasitica,25:4851(Abstr.Rev.appl.Ent.(A),58-398.

11. Prowidenti,R.and J.H.Hunter.(1975).Bean yellow mosaic virus infection in Cladrastis lutea ; an ornamental leguminous tree plant . Dis..Reprt.59:86-87.

12. Thottappilly,G.K.F.Harris and J.E.Bath.(1976).Identification of top-rolling strain of yellow mosaic virus from Michigan broadbean .Rev.Plant.Path.55:4378.

13. American Society for microbiology report. (1999).

14. Ross,S.(1964). Identification of plant viruses in plant virology.by M.K.Corbett and H.D.Sisler.Univ.of Florida press, Gaineville,U.S.A.

15. Noordam.(1973).Identification of plant viruses methods and experiments ,center for Agricultural publishing and documentation, Wagenining, Nwtherland.

16. Bos,L.(1970).Bean yellow mosaic virus No.40in" Description of plant viruses .Commonwealth mycological institute Association of Applied biologist, Survey England.

17. Kono,T.and C.S.Papp.(1977). Hand book of Agricultural pests (Aphids ,Thrips ,Mites, Snales ,Slugs). Department of food and Agriculture, Division of plant industries state of California.

18. DeBokx,J.A.,(1972). Viruses of potato and seed potato production. Center for Agriculture publishing and documentation.Wagenining,Netherland.

$$
\begin{aligned}
& \text { 19. العاني , رائد رؤوف مصطفى ـ (1995) تشخيص وتنقية فايروس البطاطا ام }
\end{aligned}
$$

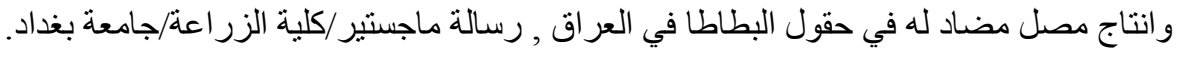

20. Williamson,D.L.(1982).Serological characterization of spiroplasma and other mycoplasma.pages 240-267."hn plant and insect mycoplasma Techniques .M.J. Daniels and P.G.Markham,eds.Croom Helm,London.

21. daRocha, A. Ohki., S. T.and Hiruki,C. (1986). Detection of viruses and mycoplasma like organismes in situ by indirect immunoflouresence microbiology .Phytopathology.76:864-868.

$$
\begin{aligned}
& \text { 22. العاني , رقيب عاكف و ياش بال راثي 1984) . فايروسات النبات ـ أساسيات التجارب العملية , وزارة }
\end{aligned}
$$

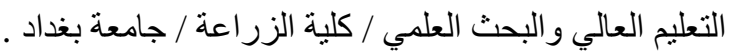

23. Zaumeyer,W.J.and H.H.and Fisher. (1953). A new necrotic-lesion producing strain of yellow bean mosaic. Phytopathology .43:45-49. 
24. Thomas,H.R. and W.J.Zaumeyer.(1953). A strains of yellow bean mosaic virus producing local lesion on tobacco. Phytopathology.43:11-15.

25. Nagaich, B.B.and K.S.Vashisth.(1965). Studies on transmision of broadbean mosaic virus by Aphis craccivora, Indian.J.Entomol..24:188-189.

26. Allam,E.K. and E.A.El-Kady. (1966).A virus causing a mosaic disease of broadbean and its' vector Aphis craccivora in Egypt. Entomologia exp.appl. 9:413418.(Abst.Rwv.Appl.Ent.(A)55:405)

27. Gaudchau,M.(1978). Studies on the transmission of bean yellow mosaic virus (BYMV) by aphids.Zcitschrift fur pflanzenkrankheiten und P flanzenshutz .85:347357. 